\title{
FLOODS RISK ASSESSMENT IN BULGARIA
}

\section{Venelin Tsankov Makakov, ${ }^{1}$ Rositsa Todorova Velichkova, ${ }^{2}$ Iskra Sashova Simova, ${ }^{3}$ Detelin Ganchev Marko ${ }^{4}$}

\begin{abstract}
Floods continue to be the most economically devastating natural disaster in the world. Worldwide, there are a lot of laws and regulations addressing this problem, as well as different models and approaches developed for flooding risk assessment at different stages of urban planning. The aim of this work is to review the existing measures for prevention of floods that threaten the security of the human population, flora and fauna. The study focuses on the necessary measures which must be implemented to tackle the problem, and early warning of population in emergency and disaster situations in order to reduce damage from floods. Existing statistical data is reviewed and analyzed and, as a consequence, recommendations are proposed.
\end{abstract}

UDC Classification: 502 ; DOI: http://dx.doi.org/10.12955/cbup.v5.1105

Keywords: floods, prevention, risk assessment, Bulgaria

\section{Introduction}

Of all environmental disasters, floods are the most studied (Mardirosyan, 2002). According to United Nations data, every year about 10,000 floods happen worldwide, having different parameters and causing various types of large-scale damage and losses.

Long-term studies have been conducted, aiming to analyze past floods throughout the country, their causes, consequences, and measures which are taken to limit their effects in urban systems.

The Ministry of Environment and Water, the Ministry of Emergency Situations, the "Civil Protection" agency, the official pages of the press and several internet sites were used as sources of information for this paper. The data is summarised by conventional methods.

The aim of this study is to examine the nature and consequences of flooding for ecosystems and urban systems in Bulgaria.

Floods are natural phenomena that are unavoidable. For Bulgaria, they are identified as the most significant type of natural disasters, which have inflicted damage reaching hundreds of thousands of euros in the last few years.

The majority of floods are natural processes, and can occur at any time and anywhere. Different types of floods create different dangers to humans and to objects of residential, industrial or critical infrastructure, and the environment. This is due to varying water level, speed and degree of occurrence, and some other hazards associated with them.

Along with the damage they cause, floods, as natural phenomenon, play an important role in maintaining the balance of nature. They are important environmental factors for the maintenance of aquatic ecosystems. Unlike other natural disasters, floods are subject to a significant degree of foresight in terms of generation and distribution, and in terms of possible consequences. Although they are natural phenomena, their appearance is largely influenced by human activity and human interference in natural processes.

The damage caused by the floods in the recent years is an indication that society is not sufficiently prepared to confront this growing risk. It has been found that the activities performed in flood protection are insufficient and need to move to a policy of comprehensive management of flood risks in terms of „coexistence” with the floods. The aim is to achieve a reduction of future risks through research, evaluation and impact of all factors that influence the onset of the floods, and the importance of their impact on human health, business and the environment. Such a comprehensive approach to managing flood risks was introduced by the 2007/60/EU Directive - European Floods Directive.

The 2007/60/EU Directive on the assessment and management of flood risks, also known as the Floods Directive, regulates the framework for assessment and management of flood risks in the

\footnotetext{
${ }^{1}$ Technical University of Sofia, vmakakov@ abv.bg

2 Technical University of Sofia, rositsavelichkova@abv.bg

${ }^{3}$ Technical University of Sofia, iskrasimova@gmail.com

${ }^{4}$ Technical University of Sofia, detmar@abv.bg
} 
Member States of the European Union. It aims to create conditions for reducing the adverse impact floods have on human health and the environment.

Careful planning of the management of flood risk allows governing bodies to develop a better system for flood risk reduction stemming from all available sources, and to set the priorities for management.

The main objective of the plan is to prepare and protect the public and the environment which are at risk by fulfilling the strategic aims and by the implementation of the provided measures,

\section{Preliminary assessment of flood risk}

In compliance with the requirements of Directive 2007/60/EU, which are fully implemented in Chapter 9, Section II of the Bulgarian Water Act, for each region of basin governance, a preliminary assessment of flood risks is made. The assessment includes:

1. Maps of the region for basin governance of water in appropriate scale, which show the topography and land use and also the boundaries of:

a) river basins and sub-basins

b) coastal regions

2. Description of occurrence of past floods with significant adverse effects on the human health, the environment, the cultural heritage, the infrastructure and business, and for which there are indications for future repetition.

3. Scale of the floods, their distribution, and assessment of their adverse effects

4. Assessment of eventual adverse effects of future floods on the human health, the environment, the cultural heritage, the infrastructure and business and taking into account as much as possible:

a) Topography, the position of watercourses and their general hydrological and geomorphological characteristics, including the retention lowlands as natural water retention areas;

b) Efficiency of man-made infrastructures (systems and equipment) for flood protection, location of populated areas, and long-term development plans;

c) Influence of climate change on flood occurrence.

According to the Water Act, in Bulgaria there are defined spate areas called "Project units." The methodology sets criteria for determining the boundaries of the project units with aim to optimize the work. Bases for determining the project units are major river basins, some of which are divided into two or more units. The main criteria for separation of project units are the areas of the basins (fig.1).

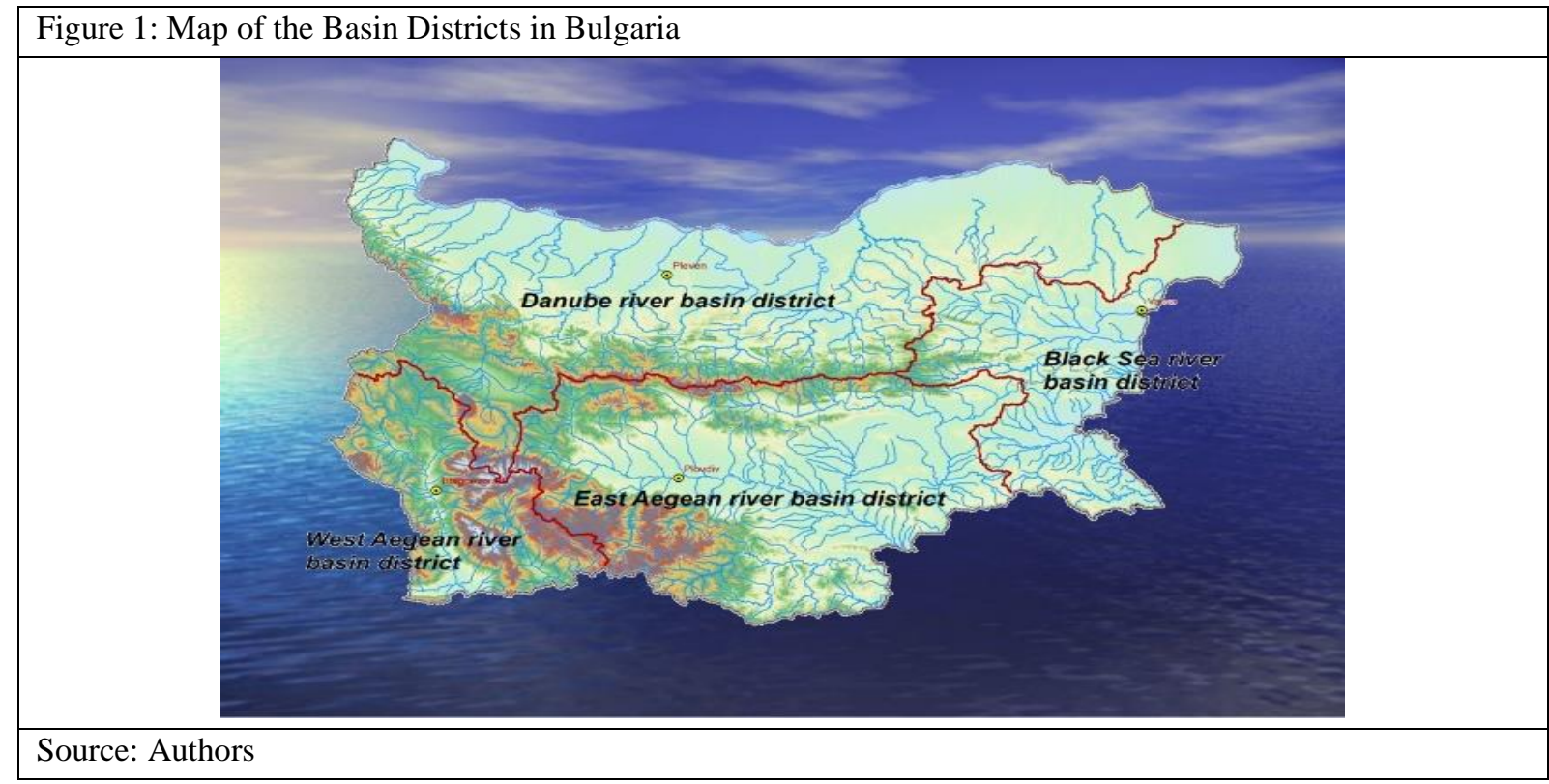

The main steps according to methodology include:

- Collection of information on past floods and processing the collected data

- Determination of areas affected by floods - distribution of potential future floods 
- Determination of potential significant flood damage - based on the information of past floods and on the potential threat of future floods.

The methodology identifies possible sources of information on past floods, and also provides a standardized questionnaire for gathering information from the municipalities. Sources and recommendations regarding the requirements and use of information on damage assessment in the four categories "Human Health," "Human Activity," Environment" and "Cultural Heritage" are given as well (Fig.2):

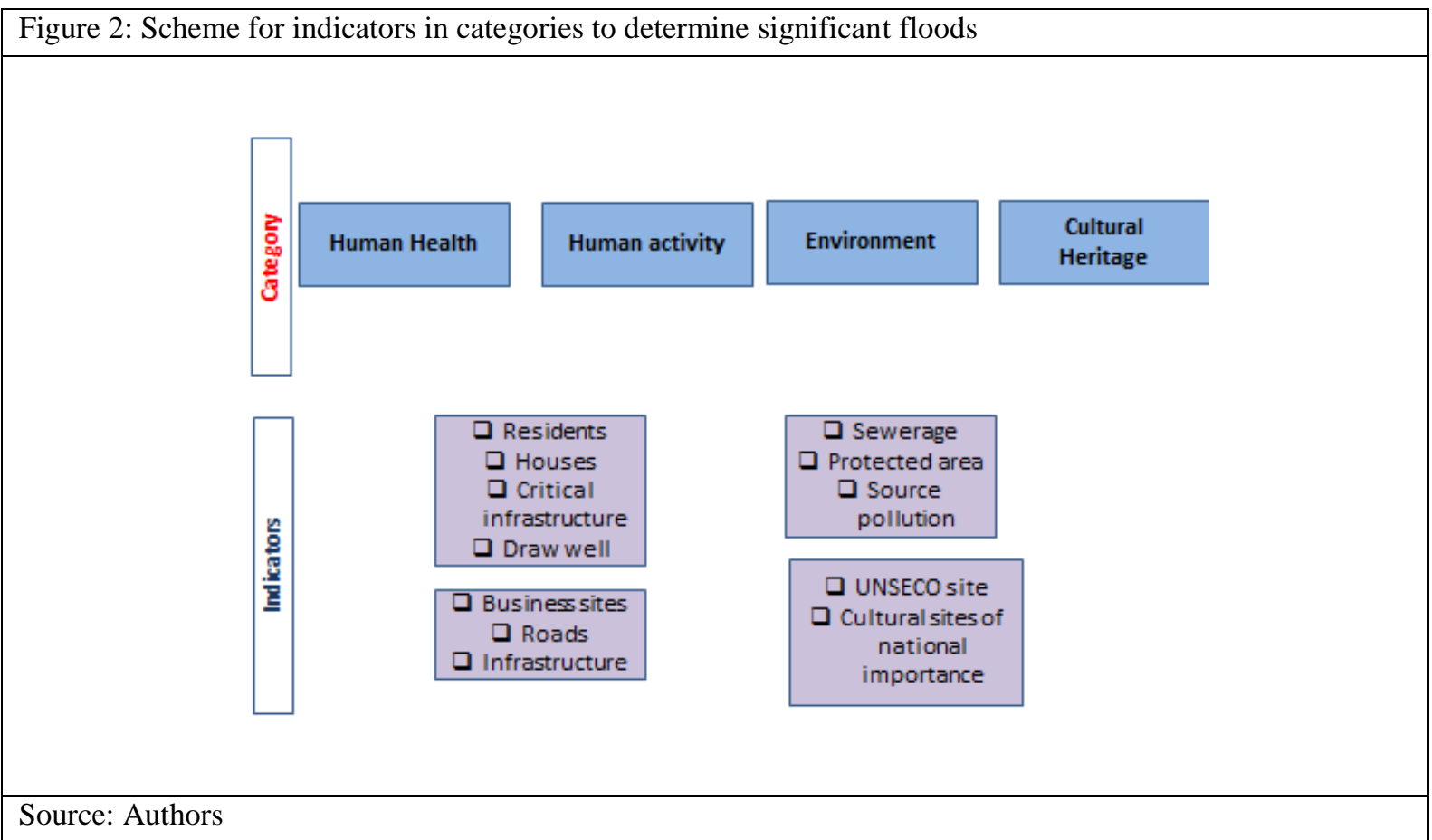

It is assumed that the threshold is exceeded if at least one of the indicators in any of the categories determines the flood as significant. The assessment of the significance of the effects of past floods is done separately for each populated place if information for registered floods according to presented data is available.

\section{Past floods in Bulgaria}

European Commission's guidelines contained in the"Draft list of flood types and stand consequence" form 16.02.2011 distinguish five types of floods according to their source:

- river - caused by rain and snowmelt

- slope-caused by rain

- lake-caused from rain water inflowing in lakes

- sea - caused by sea storms

- infrastructure - caused by insufficient conductivity of sewer and drainage systems due to rainfall, and wave transferring seawater over protective embankments in the coastal areas of cities

The collected information for floods in Bulgaria covers the period 2000-2010 and refers to 2211 past floods. The reasons for their development, distributed by major river basins, are given in figures 3-6. (Management plan for flood risk for Black Sea Basin District, Management plan for flood risk for Danube Region basin District, Management plan for flood risk for West Aegean Region Basin District, Management plan for flood risk for East Aegean Region Basin District) 

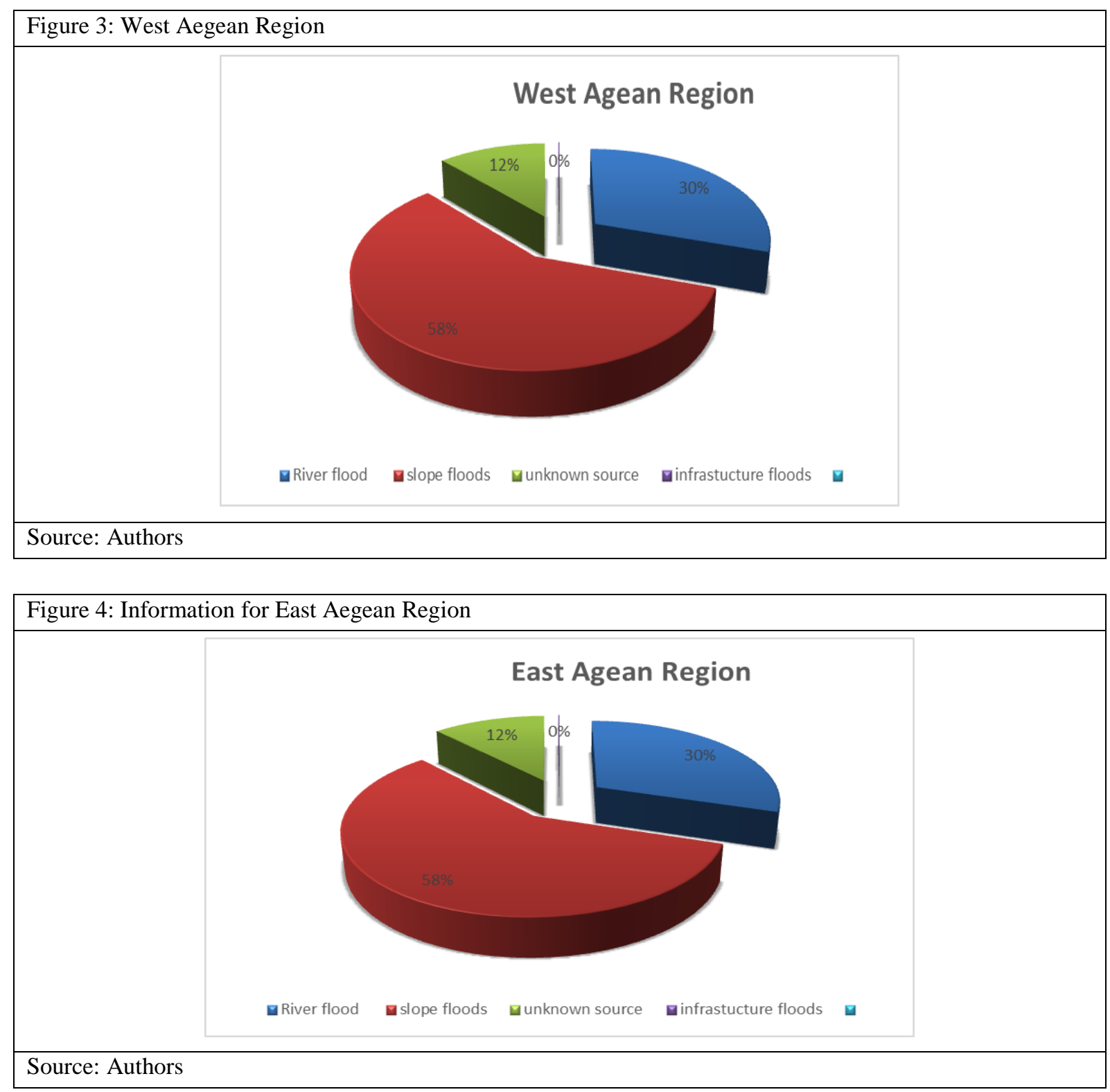

\begin{tabular}{|l|l|l|}
\hline Figure 5: Black Sea Basin District \\
\hline
\end{tabular}




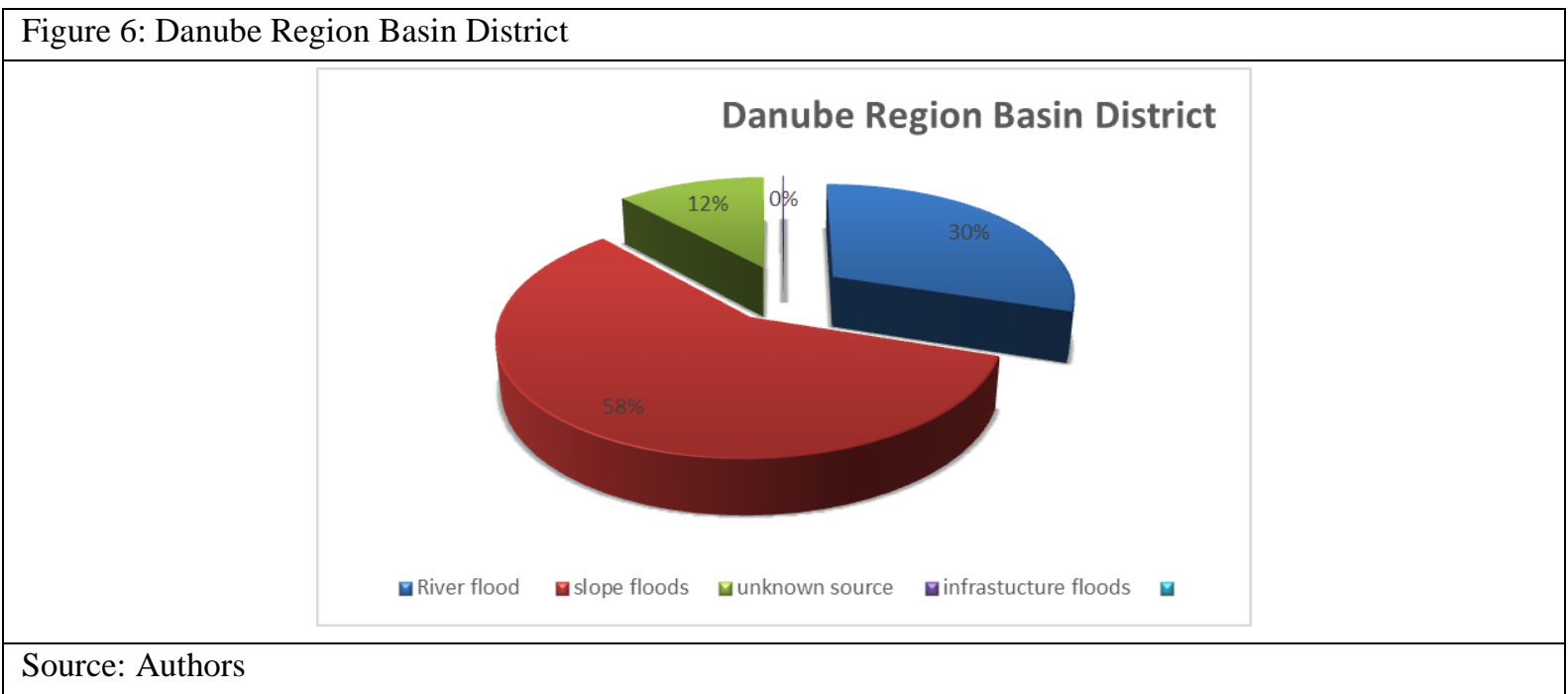

\section{Measures of risk management}

Measures for risk management of floods are determined on the bases of:

- the identified aims and priorities for risk management of floods

- national catalogue of measures for risk management of floods

- maps of the threatened regions, and maps of the regions with risk of floods.

In the context of national priorities and aims, the choice of one measure is determined by the effect that it is expected to render in following categories: "Human Health,"'Human activities,"'Environment" and"Cultural Heritage." The aim is to avoid new risks, reduce existing risks, improve endurance and increase the awareness.

In the process of selecting these measures, a general approach according to the logical scheme shown in Figure 7 is followed.

\begin{tabular}{|l|c|c|c|c|}
\hline \multicolumn{2}{|c|}{ Figure 7: Logical scheme of choice of measures } \\
\hline $\begin{array}{c}\text { Description of } \\
\text { the state }\end{array}$ \\
\hline $\begin{array}{c}\text { Defining the key } \\
\text { Issues } \\
\text { key issues }\end{array}$
\end{tabular}

Stage 1. Description of the state - at this stage the information available for preliminary assessment of floods in the regions with significant potential risk of floods is presented:

- maps of threat and risk of floods

- aims and priorities based on water infrastructure, as well the information gathered and processed in connection with past floods conclusions which are drawn from them.

Stage 2. Defining main problems - at this stage, the main problems associated with flood protection are identified and put into perspective of national priorities

Stage 3 - Formulation of possible alternatives that present several possible solutions of the problem.

Stage 4 - Selection of alternatives - Criteria for selection of alternatives are chosen, and a selection of the best alternative for each problem is made. This is linked to national priorities where level of importance of each measure is determined, and on this basis the choice of alterative evaluation criteria is made. 
Stage 5 - Selection of measures - based on the selected alternatives, filters and set of measures are selected.

\section{Conclusion}

Floods represent $40 \%$ of natural disasters worldwide. Natural floods are the results of heavy rainfall, intensive snow melting, stagnation of watercourses, etc.

In the preventive organizational activities, derived from experiences with the serious consequences of the floods in Bulgaria in the recent years, are included the adoption of new laws and instructions, strengthening the role of the Integrated Rescue System, and operational communication - information centers in the territories of each region are under construction. However, there is a need for the development of more measures for prevention, control and scientific prediction of possible disasters related to water storms, or floods.

\section{References}

DIRECTIVE 2007/60/EC OF THE EUROPEAN PARLIAMENT AND OF THE COUNCIL of 23 October 2007 on the assessment and management of flood risks (Text with EEA relevance) Official Journal of the European Union, 6.11.2007

http://ec.europa.eu/environment/water/flood_risk/index.htm

http://www5.moew.government.bg/?page_id=23341

Management plan for flood risk for Black Sea Basin District

Management plan for flood risk for Danube Region basin District

Management plan for flood risk for East Aegean Region Basin District

Management plan for flood risk for West Aegean Region Basin District

Mardirossian, G. (2009), Природни бедствия и екологични катастрофи - изучаване, превенция, защита, [Natural disaster and ecological catastrophes - study, prevention, protection] (2nd edition), Sofia: Prof. Marin Dirnov Publishing House 